\title{
MORTEROS DE REPARACIÓN CUYO COMPONENTE BÁSICO ES EL CEMENTO PORTLAND*
}

\author{
(REPAIR MATERIALS BASED ON PORTLAND CEMENT)
}

Francisco Garcia Ruiz,

\section{RESUMEN}

En el presente trabajo se trata de facilitar información sobre las técnicas o sistemas de ejecución de reparación de hormigones con materiales cuyo componente básico es el cemento portland.

Esa información se refiere por tanto a lechadas colocadas por vertido o bombeo, gunita, microhormigón colocado por bombeo y hormigones inyectados. Se proporcionan sobre esas técnicas una serie de comentarios, datos y denominación de normas de control.

También se trata el problema de las deformaciones de acusada importancia en este tipo de trabajos y de alguna de las soluciones que suelen utilizarse.

\section{SUMMARY}

This work try to facilitate information about techniques or sistems for the mending of concretes with materials whose basic component is "Portland" cement.

So, this information refers to insert pastes through insertion or camber, gunita, microconcrete insert through camber and inyects concretes. Are provides, about these techniques, a sequence of coments, facts and designations of control norms.

Is also comented the problem of the deformations very pronounced in this kind of jobs, and the solutions to use generally.

\section{INTRODUCCIÓN}

Se trata de comentar la información de que se dispone sobre lechadas, morteros y hormigones de reparación, cuyo componente básico es el cemento portland. En estos materiales de reparación se puede utilizar todos los tipos de cemento que incluye la actual Instrucción Española EH-88. Los más utilizados en reparaciones, según experiencia propia, son los tipos 350 y 450.

Las estructuras a reparar, en donde se utilizan estos materiales, son las de hormigón en masa o armado. Por costumbre se denomina soporte a la estructura a reparar, y se sobreentiende que con las limitaciones lógicas debidas a la naturaleza del soporte estos materiales de reparación pueden aplicarse a fábricas de ladrillo, mampostería, etcétera.

* Ponencia presentada en el seminario S.12 del Curso CEMCO-88 sobre diagnosis, protección y reparación de obras de hormigón (6-VI-88), organizado por el IETcc y el GEHO.
Estos materiales se pueden utilizar como: lechadas, morteros y hormigones, comentando seguidamente - en cada una de estas formas - los sistemas o téc. nicas de ejecución más utilizados en reparaciones. No se mencionan, entre esas técnicas, las de puesta en obra y compactación convencionales que, a veces, es posible y adecuado utilizar cuando las dimensiones y accesibilidad a la zona a reparar lo permiten.

\section{LECHADAS}

Se define la lechada como el material compuesto por cemento y agua. En reparaciones, la utilización de lechadas se reduce normalmente a dos clases: la ligera y la densa. La primera de ellas tiene una relación agua/cemento del orden de la unidad. Es un material de los denominados "inestables" para su colocación por vertido o bombeo. La colocación se realiza, prácticamente, por decantación de los granos de cemento.

Este tipo de lechada se aplica para relleno de fisuras inferiores a un milímetro. Actualmente su empleo se 


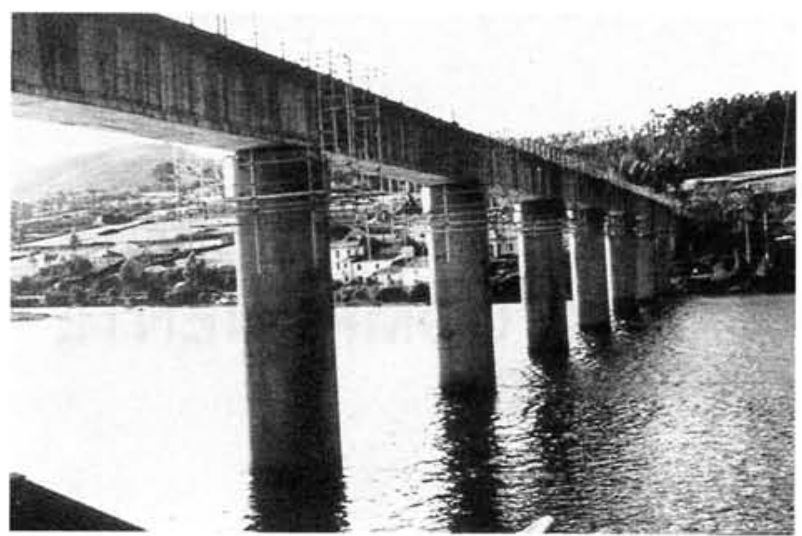

Fig. 1

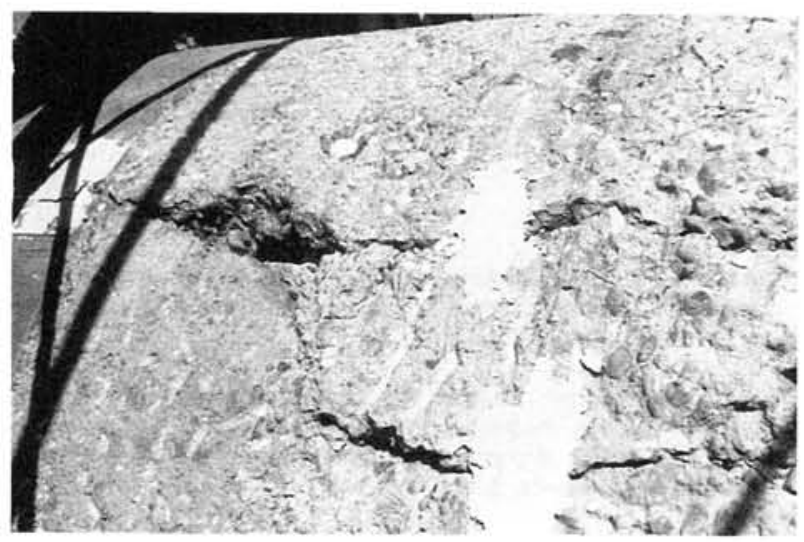

Fig. 2

reduce a los casos en que la inyección con resinas no es aconsejable por algunas condiciones especiales del soporte: dimensiones, temperatura, presencia de agua, etcétera.

La resistencia a compresión de estas lechadas no suele alcanzar los $100 \mathrm{~kg} / \mathrm{cm}^{2}$.

Para estas lechadas es recomendable el uso de aditivos con objeto de reducir la exudación o "bleeding" y retrasar la iniciación del fraguado. El ensayo ASTM C-937-80 facilita la información sobre lo adecuado de usar el aditivo.

Otro tipo de lechada (la densa), que se emplea en reparaciones, es el que tiene una relación agua/cemento del orden de $1 / 2$. Es un material "estable" para su colocación por vertido o bombeo. La colocación no altera las características del material, que se consiguió al terminar la fase de mezclado.

Este tipo de lechada se utiliza para rellenar grietas y juntas con espesores superiores a un milimetro. Una publicación francesa realizada en colaboración por varios organismos, entre los que se cuenta la Asociación de empresarios especializados en trabajos de reparación y refuerzo, considera los rellenos de grietas o jun- tas entre 1 y $10 \mathrm{~mm}$ como el campo idóneo de aplicación para estas lechadas de cemento. Otra utilización muy extendida es como complemento de morteros colocados por bombeo en relleno de coqueras y grietas de espesor variable. Ésta, como "primer", consiste en el bombeo inicial de un cierto volumen de lechada a la que desplaza, en parte, el mortero inyectado a continuación en las zonas por donde puede penetrar el mortero, quedando los espacios más estrechos rellenos de lechada. La resistencia a compresión de estas lechadas suele ser del orden de los $400 \mathrm{~kg} / \mathrm{cm}^{2}$.

La utilización de un aditivo similar o idéntico al utilizado en los morteros, colocados por vertido o bombeo, es aconsejable para conseguir la calidad que interesa obtener en los trabajos de reparación.

La Figura 1 muestra un tramo del puente de FEVE, sobre la Ria de Navia, donde se emplearon varias técnicas de ejecución, hormigón inyectado, microhormigón y bulonado con inyección de lechada densa.

La Fig. 2 indica el tipo de agrietamiento de algunas pilas de hormigón en masa. En el tratamiento de esas zonas también se empleó el bulonado con inyección de lechada densa.

\section{MORTEROS}

Se define al mortero como el material compuesto por cemento, agua y árido fino a arena que, según la EH-88, corresponde al árido que pasa por el tamiz de $5 \mathrm{~mm}$ de luz de malla.

Las técnicas de ejecución más utilizadas son el gunitado y el microhormigón. La gunita puede considerarse mortero u hormigón, según el tamaño máximo de árido que se utilice. La Norma $\mathrm{ACl}$ admite tamaños máximos desde 2,4 a 19,1 mm y tamices 8 y $3 / 4$ de las ASTM. La utilización del gunitado, como técnica de ejecución de morteros y hormigones de reparación, consigue un material de calidad adecuada. La compactación enérgica sin segregación y la relación agua/cemento reducida, del orden de un 0,45 , permiten obtener fácilmente, con una dosificación de $400 \mathrm{~kg}$ de cemento, las características de un $\mathrm{H}-400$ y, en consecuen$\mathrm{cia}$, sin que las deformaciones independientes de la tensión (retracción y termohigrométricas) merezcan una atención especial para los proyectistas.

La adherencia, si se trata la superficie del soporte adecuadamente, es del orden de la que se obtiene con hor. migones inyectados y que se comentará posteriormen- 
te. Cuando se utiliza esta técnica no se usan aditivos, ya que realmente no son necesarios como en las otras técnicas de ejecución.

Para conseguir un material de esa calidad es necesario que concurran las condiciones siguientes:

- La zona a reparar debe tener acceso abierto por donde puede penetrar, sin mayor dificultad, el chorro que se proyecta.

- Debe situarse la boquilla de proyección a la distancia adecuada, función del diámetro de la boquilla.

- El soporte habrá recibido un tratamiento al menos de limpieza con agua y aire.

- La gunita será realizada por personal experimentado.

Si no se cumplen esas condiciones, el material in situ obtenido será un material poroso, como un enfoscado cuya caracteristica no llega, a veces, a un $\mathrm{H}-200$.

Otro problema que puede presentar la gunita es el acabado rugoso, que se obtiene cuando se utiliza árido grueso. Para mejorar el acabado se acostumbra a utilizar uno de los dos sistemas siguientes:

- bien realizar una capa final de poco espesor con árido más fino, o

- bien mediante un fratasado con mortero fino convencional para igualar la superficie; este sistema, cuando se aplica sobre gunita cuyo fraguado no se ha iniciado y se aplica con cierta energia, suele descompactar en algún espesor la gunita.

Entre las Normas ACl se encuentran la "Recomended Practice for shotcreting" (ACl 506.66) y la "Specification for materials. Proportining an aplication of shotcrete" (ACl 506.2.77) con recomendaciones que no se considera necesario repetir aqui.

La Fig. 3 muestra una grieta en el estribo del Puente del Camello sobre ferrocarril, en Villaverde, cerca de Madrid. Preparando el soporte con un picado adicional, se puede tratar con gunita esa grieta en el muro, de $0,40 \mathrm{~m}$ de espesor, dentro del tratamiento general de toda la superficie de los estribos.

En la Fig. 4 se observa el aspecto de una zona de tratamiento en dos fases de dichos estribos. La Fig. 5 muestra un tratamiento de unos silos en dos fases. El siste-

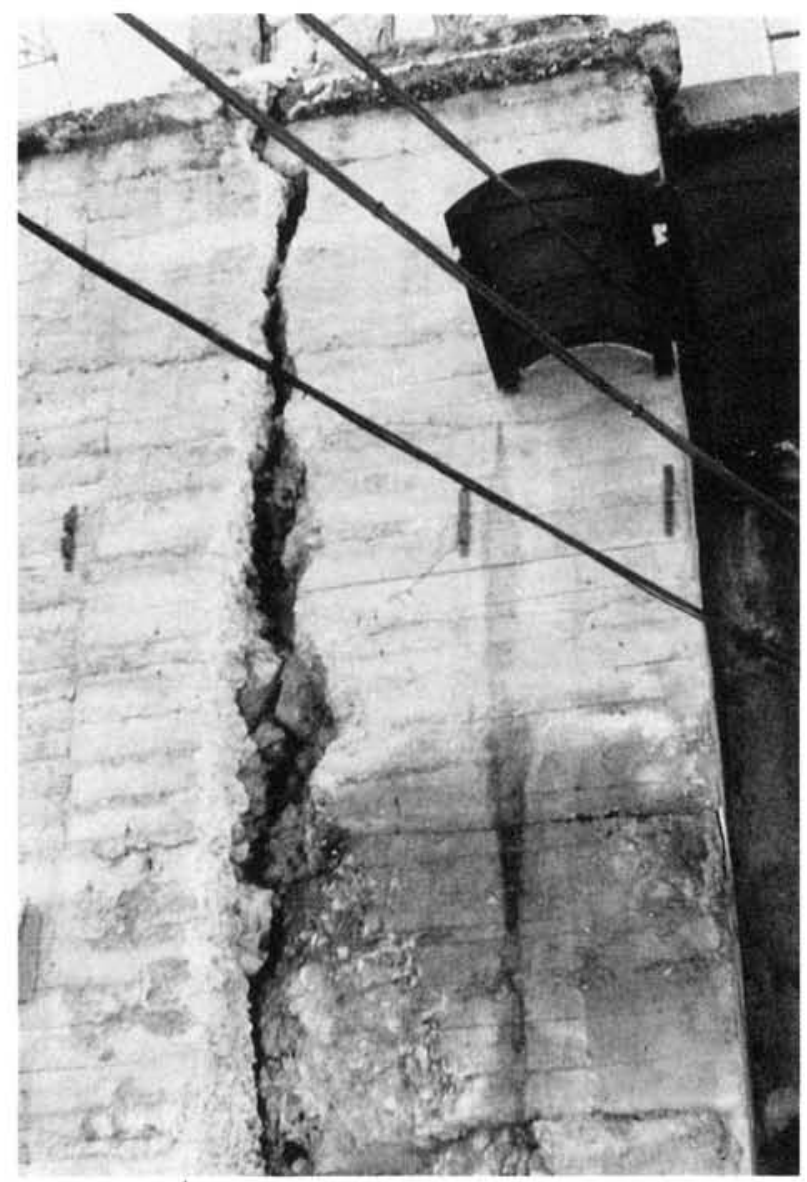

Fig. 3

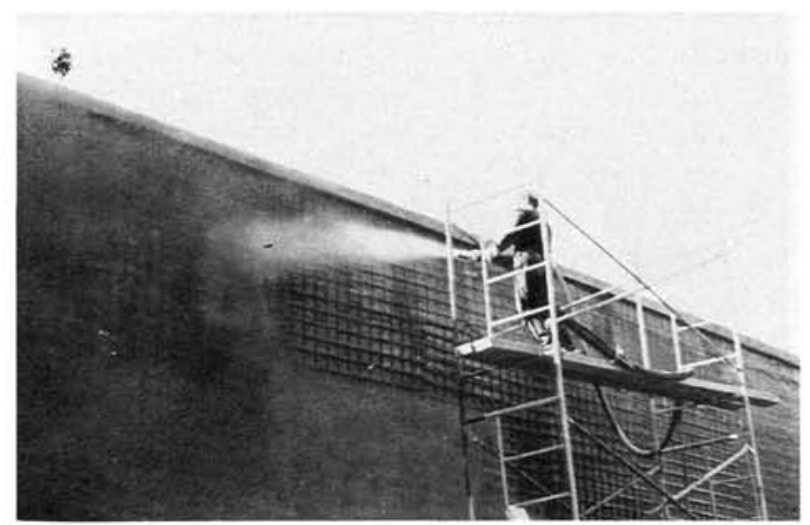

Fig. 4

ma consiste en realizar una primera capa de 2 a $3 \mathrm{~cm}$ sin armar, con objeto de poder gunitar sin obstáculos, los cuales impiden conseguir una buena adherencia. Sobre esa capa inicial se apoya y se ata la armadura. En la Fig. 6 se puede ver la realización de la segunda capa que cubre la armadura sin problemas de interferencias que podria reducir la calidad detrás de ella. La adherencia entre capas realizadas con un desfase que no supere las 24 horas, no ofrece prácticamente discontinuidad apreciable en las muestras obtenidas por sondeo. 


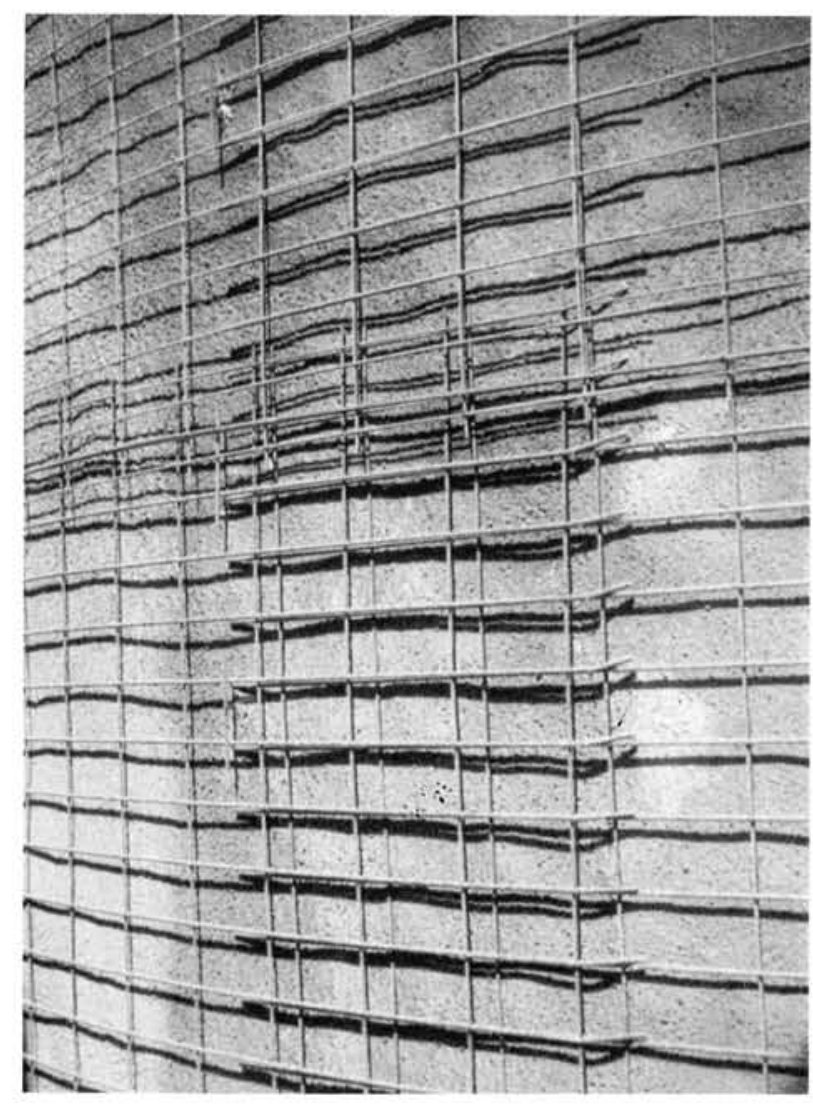

Fig. 5

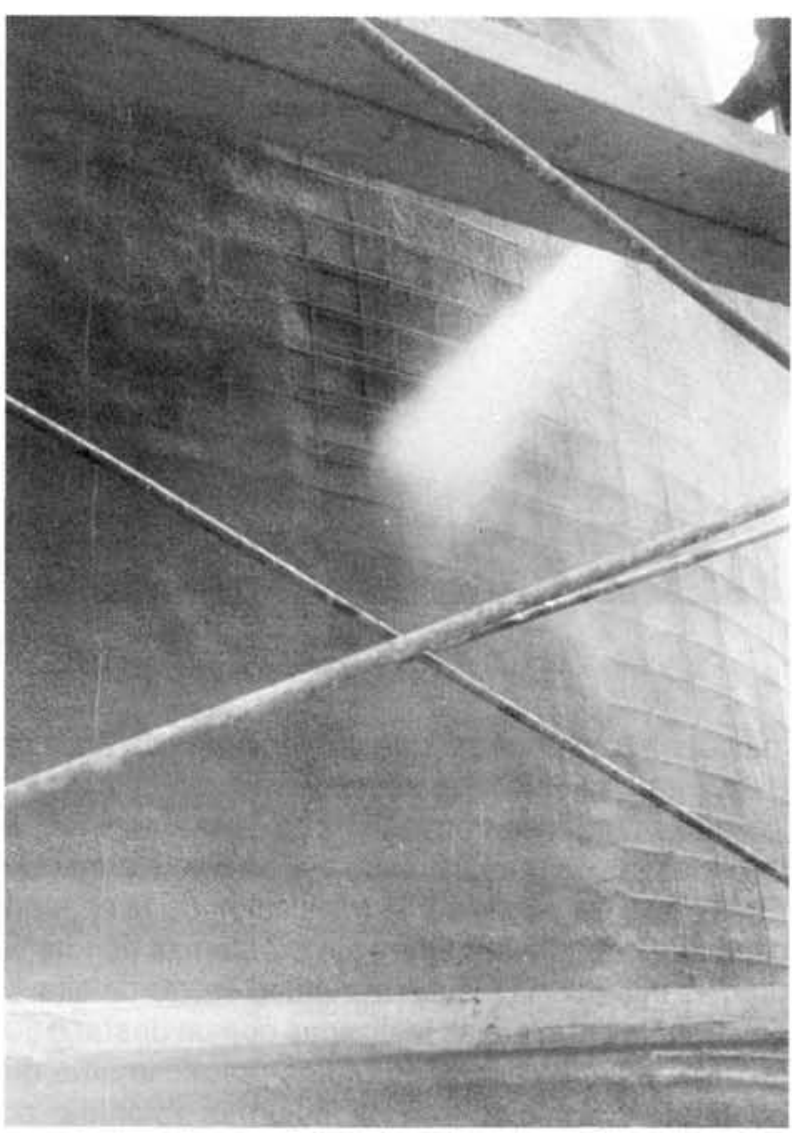

Fig. 6

(c) Consejo Superior de Investigaciones Científicas Licencia Creative Commons 3.0 España (by-nc)

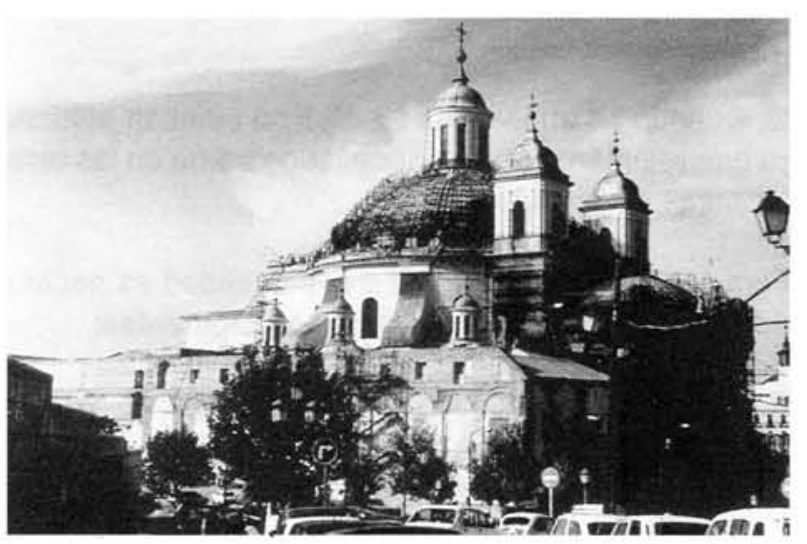

Fig. 7

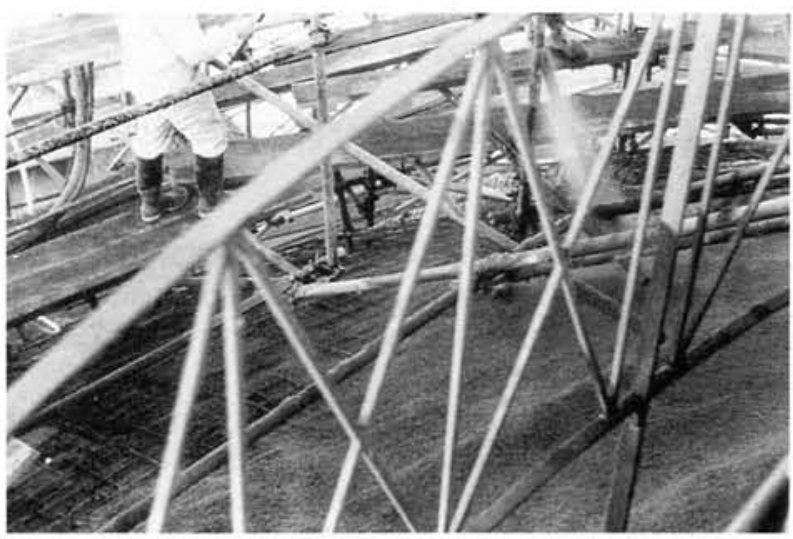

Fig. 8

El gunitado también se utiliza con frecuencia en edificación y en la reparación de pilares y vigas, que con unos encofrados de esquina permiten marcar las aristas, lo cual es una práctica corriente. El recrecido por la parte inferior de forjados de hormigón es otra práctica normal.

También se utiliza en reparación de canales. En las zonas donde discurre el canal sobre terreno permeable conviene asegurar al máximo la impermeabilización del revestimiento y se usa como complemento de una lámina plástica continua. La gunita protege y subsana cualquier defecto puntual de la lámina que pudiera producirse.

En la Fig. 7 se observa la cúpula de San Francisco el Grande, en Madrid, la cual tenia un problema de falta de impermeabilidad. En la Fig. 8 se aprecia el gunitado sobre la capa de poliuretano, con el que se ha recubierto la fábrica de la cúpula*.

•Ver "Informes de la Construcción”, n. 399, pág. 5. http://informesdelaconstruccion.revistas.csic.es 


\section{MICROHORMIGÓN}

Como ya se indicó anteriormente la técnica de ejecución en reparaciones con mortero más utilizada es el microhormigón. Éste es un mortero preparado para ser colocado por bombeo, en el que el tamaño máximo de la arena se limita a 2,4 mm (tamiz n.. 8 de las ASTM) $y$ al que no se puede someter a compactación.

Para conseguir un producto de la calidad que se requiere en reparaciones es preciso un aditivo complejo que actúe sobre varios problemas que se plantean con el uso de esta técnica. La cantidad de agua se determina con un cono de fluidez (flow-cone). En la CRD-C79-58 del Corps of Engineers o en la ASTM C-939-81 se incluyen el tipo de cono y proceso de ejecución del ensayo. La fluidez medida en segundos suele estar comprendida entre $25 \pm 2$ segundos. Algunos pliegos de condiciones exigen que el aditivo deba permitir reducir el contenido de agua en un 20 por 100 para la misma fluidez. El ensayo ASTM C-937-80 se utiliza para comprobar el incremento de fluidez. Es normal operar con relaciones agua/cemento del orden de 0,69 con dosificaciones de $500 \mathrm{~kg}$ de cemento por metro cúbico. Esta dosificación suele proporcionar las características de un $\mathrm{H}-200$.

Con una dosificación de $650 \mathrm{~kg}$ se suele operar con una relación agua/cemento del orden de 0,56 y se consigue normalmente las caracteristicas de un $\mathrm{H}-400$.

Otro de los problemas que debe resolver el aditivo, en estos morteros fluidos por bombeo, es el mantener en suspensión dentro del mortero los granos de arena sometidos al desplazamiento por bombeo, evitando la segregación.

La EH-88 autoriza el uso de aditivo si se obtiene el efecto deseado sin perturbar excesivamente las restantes características del hormigón. El mantener en suspensión, dentro del mortero, granos de arena de $5 \mathrm{~mm}$ exigiria una cantidad límite de aditivo. Por esta causa, y la posibilidad de penetrar en zonas más estrechas, se justifica la limitación del tamaño máximo de la arena a 2,4 mm. Un mortero con tamaño máximo de árido de $2,4 \mathrm{~mm}$ circula sin coacción adicional debido a su tamaño máximo por un agujero 10 veces mayor, es decir, por un orificio de 24 milimetros.

El árido fino $o$ arena, en este mortero, puede ser natural o de machaqueo. El módulo de finura no debe ser inferior a 1,4. Tampoco debe sobrepasar los 2,1 para contenidos de cemento de $500 \mathrm{~kg}$. Para dosificaciones más elevadas puede aumentarse esa cifra, ya que los finos del cemento contribuyen a facilitar el bombeo.
Otro problema que se plantea es el de las deformaciones independientes de la tensión: las de retracción y las termohigrométricas. Para justificar los métodos que se usan con objeto de disminuir este problema se puede ver a continuación una serie de figuras donde se reflejan temperaturas y deformaciones. Se han obtenido estas figuras de bloques de hormigón inyectado y con aglomerante que contenía cenizas volantes, por lo que la posición relativa de las curvas es algo menos acusada que cuando se trata de un microhormigón con sólo cemento portland.

En el gráfico de la Fig. 9 se representa una típica curva de temperaturas de un hormigón, y la de la temperatura del medio ambiente. La deformación corresponde, en parte, a la diferencia de ordenadas entre la máxima de la curva de la temperatura del hormigón y la del ambiente correspondiente, puesto que cuando esa diferencia de ordenadas desaparece se considera que la deformación no continúa.

En el gráfico de la Fig. 10 se representa la típica curva de deformaciones correspondiente. El problema es complejo debido a que influyen otra serie de factores, como el ambiente en que se desarrolla el proceso.

En la Fig. 11 se representan tres curvas de temperaturas de un mismo bloque de hormigón, según la situación del termómetro. En la zona de la zapata enterrada del bloque, la elevación de la temperatura es bastante menor, y la deformación correspondiente sería del orden del 50 por 100 de la zona de hormigón situada a $1,50 \mathrm{~m}$ del suelo.

La temperatura medio ambiente se toma en este caso a las 8,30 de la mañana, ya que la hora es otra variable más.

En resumen, y como consecuencias prácticas, se debería considerar:

- Del aditivo, igual que en los hormigones inyectados, debe conseguirse un retraso en el fraguado y una ligera expansión antes del fraguado para disminuir la retracción inicial.

- Cuando el contenido de cemento y el ambiente tiendan a ser críticos, el cemento a utilizar debe tener una finura Blaine inferior a $4.000 \mathrm{~cm}^{2} / \mathrm{g}$.

- Cualquier sistema que reduzca el valor de la diferencia de ordenadas que comentábamos disminuye las deformaciones reversibles independientes de la tensión. Uno de los sistemas para conseguir esa reducción es usar cemento que contenga puzolanas o cenizas volantes. 


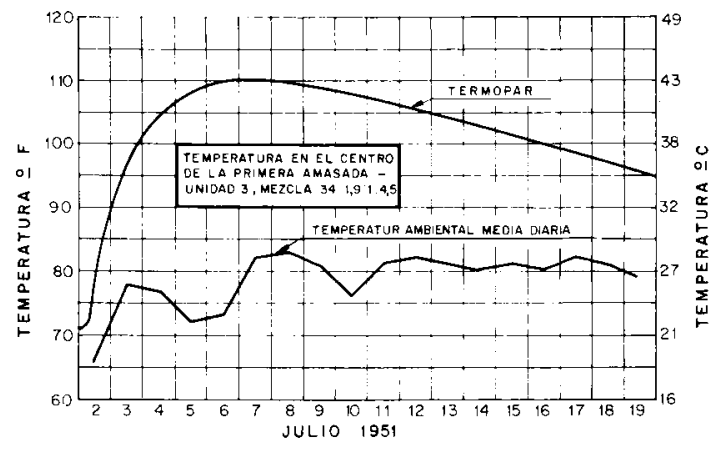

Fig. 9.-Temperaturas del hormigón, amasada, 3.

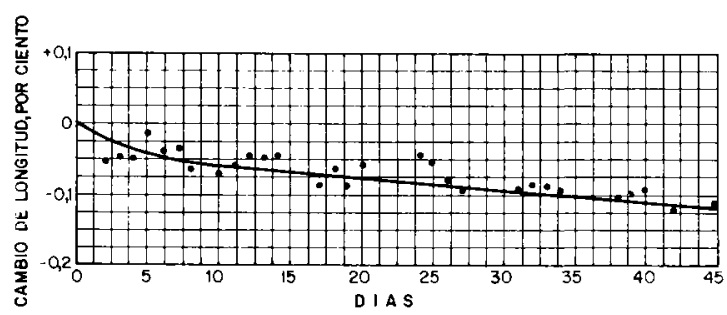

Fig. 10.-Cambio de longitud del bloque de ensayo Prepakt, medido con armadura de referencia de 18 pies, de acero inoxidable.

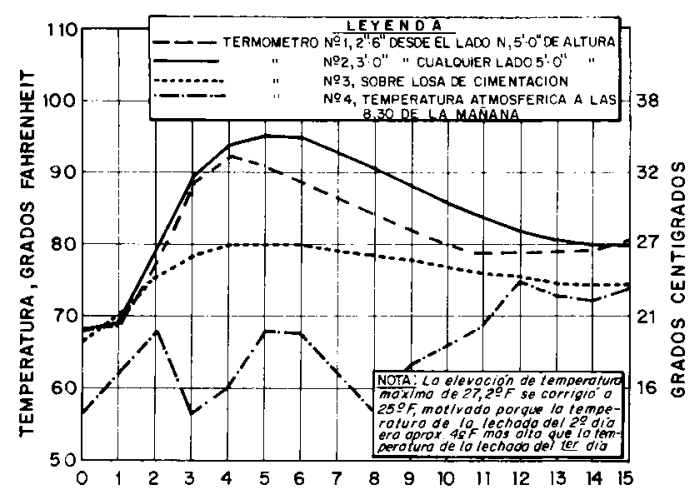

Fig. 11.-Temperatura del bloque de ensayo Prepakt.

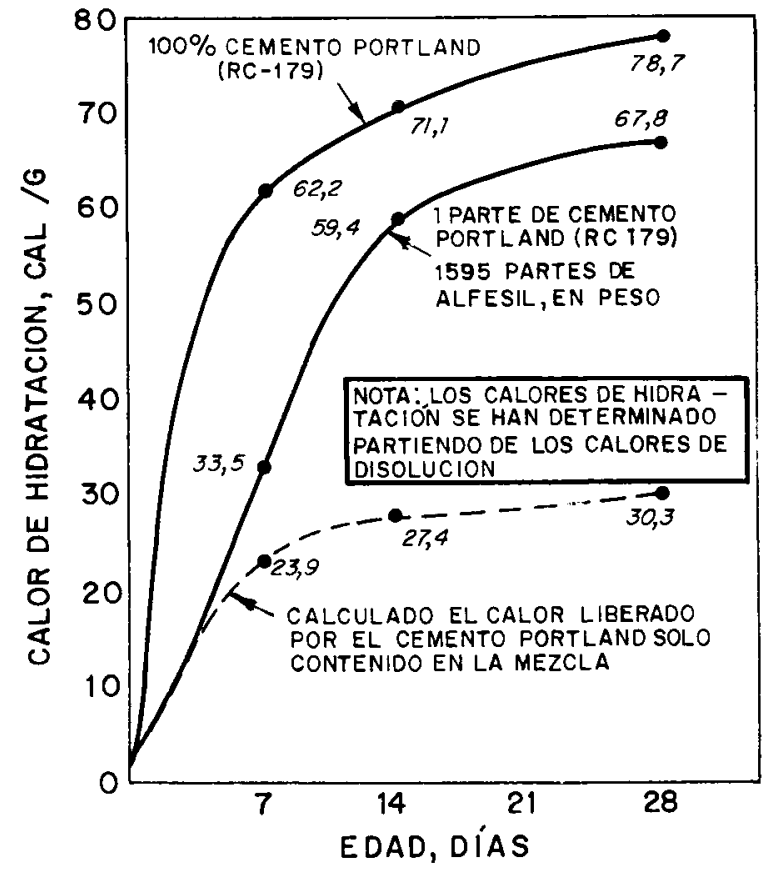

Fig. 12.-Comparación del calor de hidratación del cemento Portland y de la mezcla cemento Portland-Alfesil.

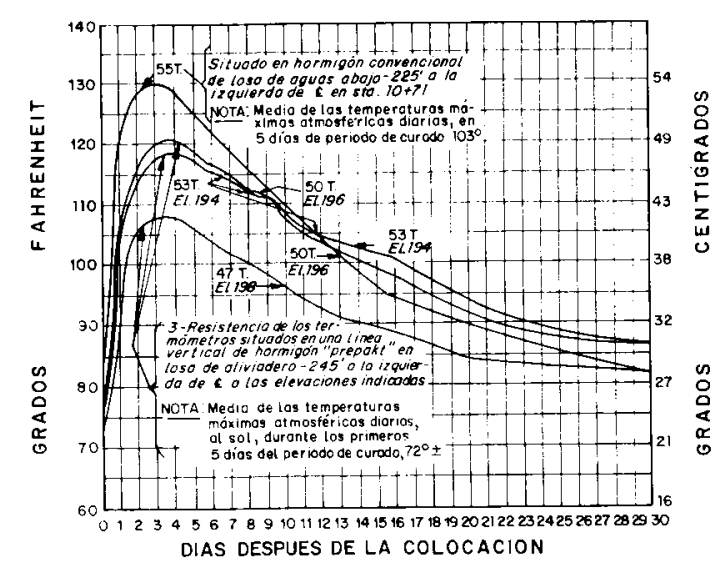

Fig. 13.-Temperaturas de hidratación en losas de aliviadero.

En la Fig. 12 se observa que el valor de hidratación de una puzolana o ceniza volante es del orden de $1 / 3$ de la que produce el cemento portland al que sustituye.

En la Fig. 13 se aprecia la disminución que se produce en el máximo de la curva de temperatura cuando se sustituye parte del cemento portland por cenizas volantes.

Otro de los sistemas consiste en enfriar los materiales para que, al partir de un punto más bajo, la diferencia de ordenadas sea menor, entre 10 y $20^{\circ}$ menos. Actualmente se realiza sustituyendo del 35 al 40 por ciento del agua de amasado por gránulos o escamas de hielo que reparten, en las grandes ciudades, durante todo el día a 8 ó $9^{\circ} \mathrm{C}$ bajo cero. La temperatura del microhormigón, al salir de la mezcladora, es de $2{ }^{\circ} \mathrm{C}$. Este sistema tiene el inconveniente de que en los cementos con un acelerado proceso de fraguado la resistencia final es claramente inferior a la que se consigue sin añadir hielo. Los cementos tipo ARI no deben utilizarse con este sistema.

Además de los ensayos mencionados se utilizan para control del microhormigón:

- Expansión y exudación ASTM-C-940-81 y CRDC-81-58.

- Retención del agua ASTM-C-941-81 y CRD-C-941.

- Tiempo de iniciación y final de fraguado con la aguja de Vicat CRD-C-82-58.

- Ensayos de resistencia a compresión en probeta cilíndrica de $15 \times 30$ y de compresión y flexión en probeta de $4 \times 4 \times 16(\mathrm{RC}-75)$.

En la figura 14 se muestra la coquera de un paso de ferrocarril que, una vez reparada con un enfoscado, la carbonatación del hormigón y corrosión del acero la ha vuelto a poner al descubierto. En la Fig. 15 se puede ver la reparación terminada. 
En la Fig. 16 se observa, una vez saneada y colocada una armadura pasiva, la avería que produjo un camión con carga a más altura que el gálibo rompiendo por el alma las tres primeras vigas de un paso superior. Se puede ver en la Fig. 17 la reparación acabada y las cabezas de las armaduras pasivas longitudinales y transversales a las que se dio una cierta tensión con llaves dinamométricas para incrementar el monolitismo del conjunto. En la Fig. 18 se observa el picado del recubrimiento para alejar las cabezas de pretensado en un paso superior, en que las flechas bajo carga superaban las previstas.

En la Fig. 19 se muestra la reparación terminada.

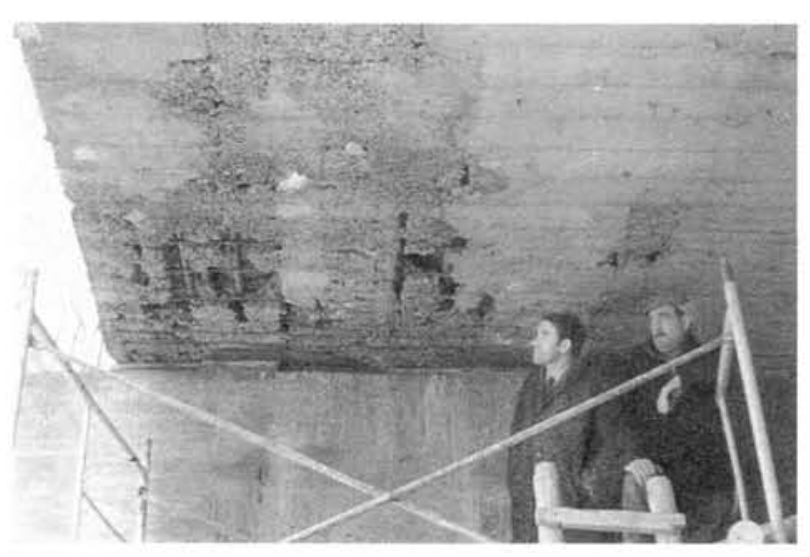

Fig. 14

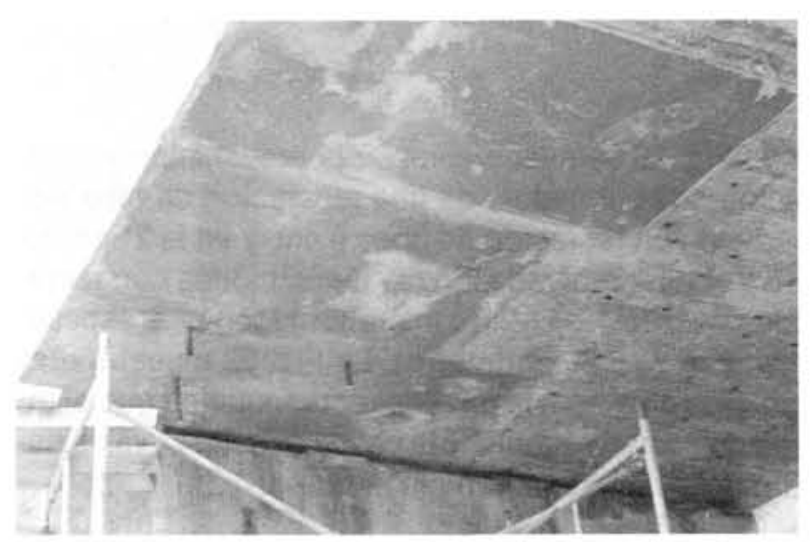

Fig. 15

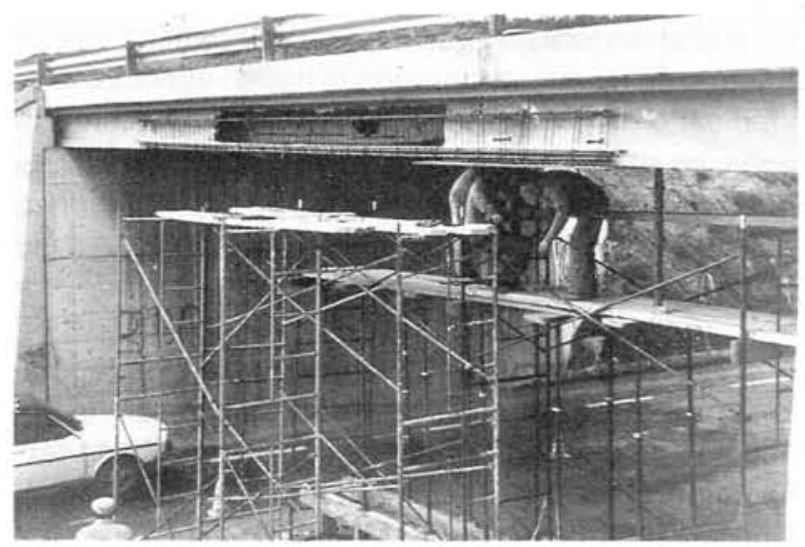

Fig. 16

(C) Consejo Superior de Investigaciones Científicas Licencia Creative Commons 3.0 España (by-nc)

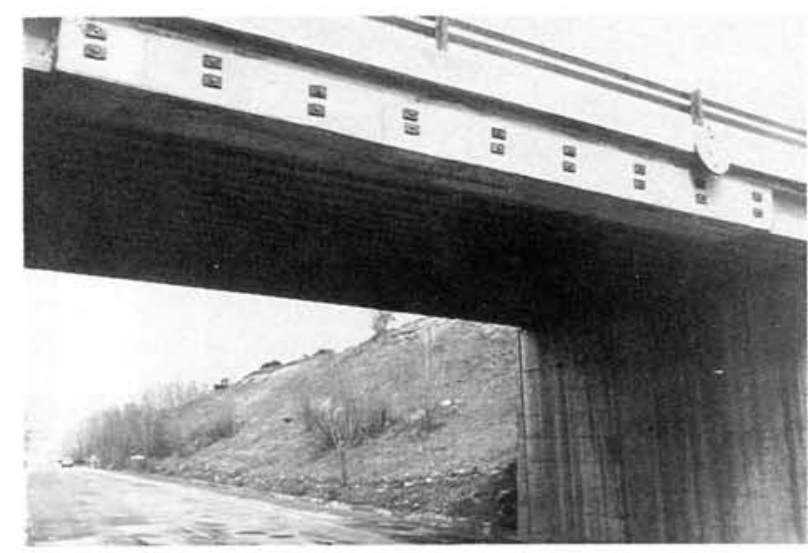

Fig. 17

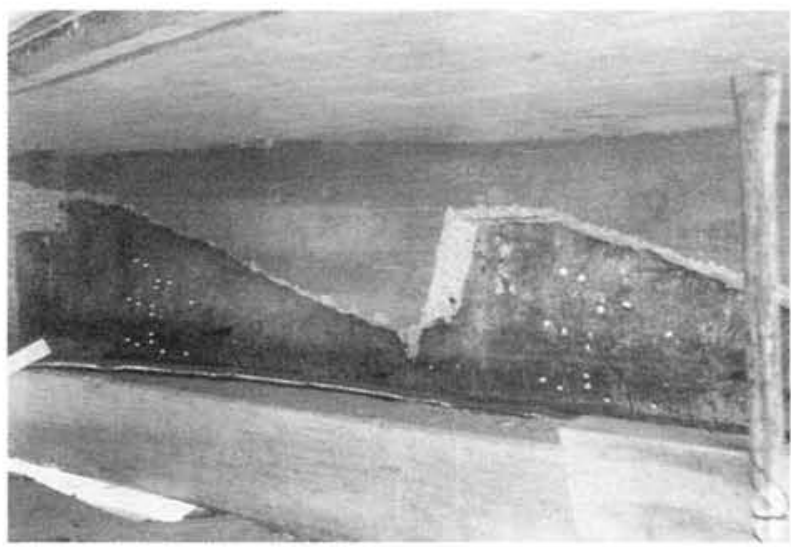

Fig. 18

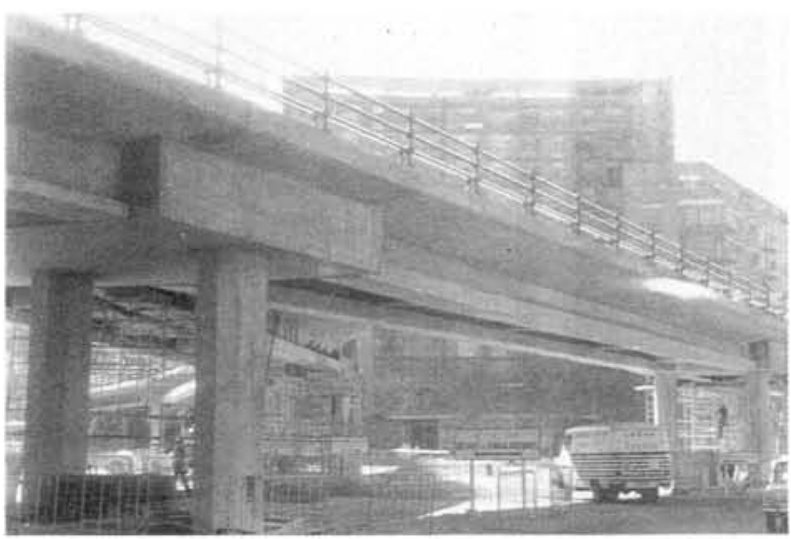

Fig. 19

http://informesdelaconstruccion.revistas.csic.es 


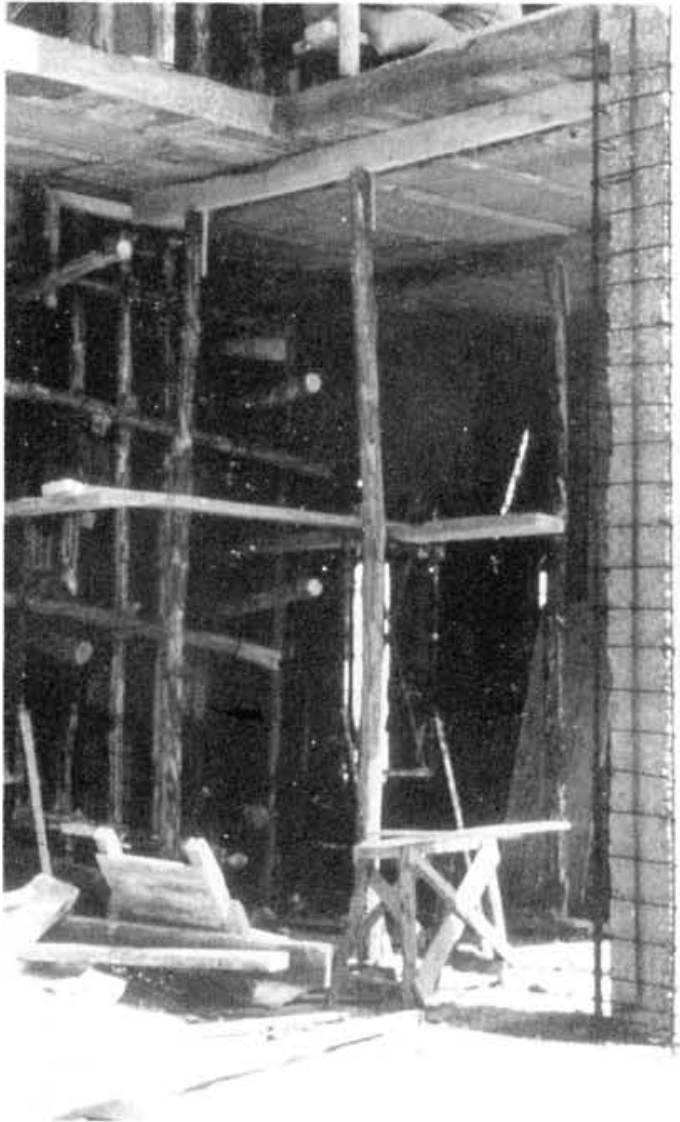

Fig. 20

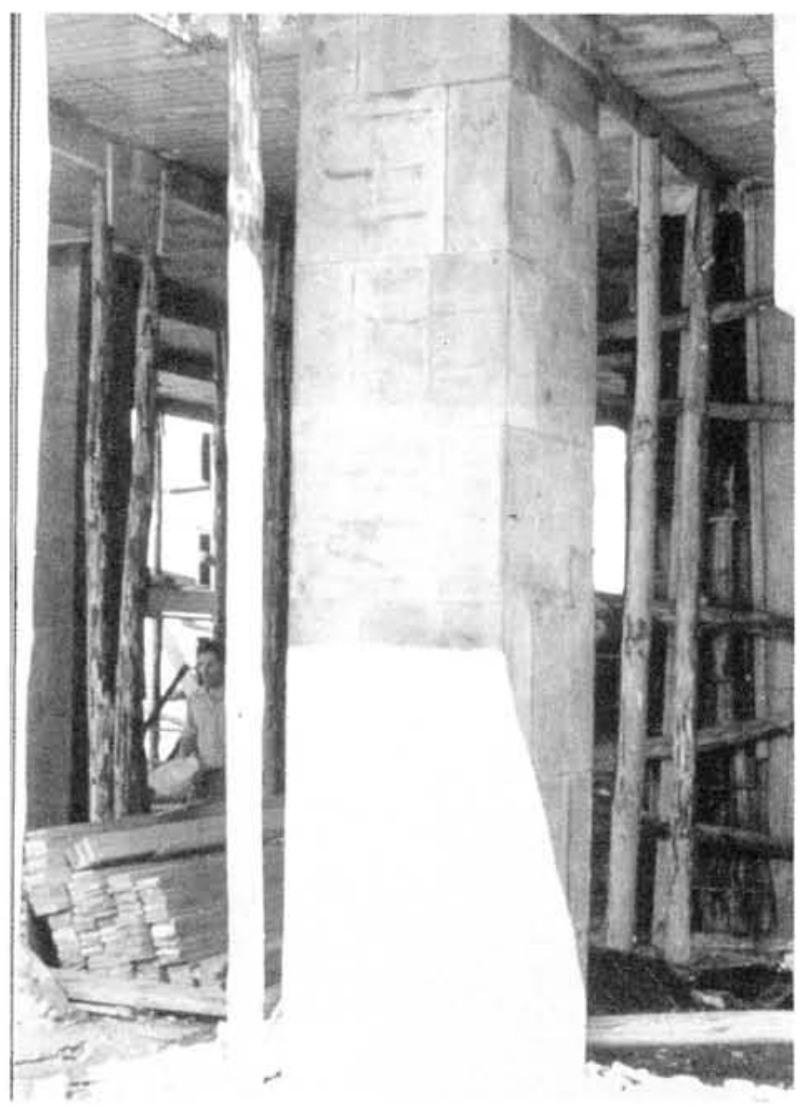

Fig. 21

(C) Consejo Superior de Investigaciones Científicas Licencia Creative Commons 3.0 España (by-nc)

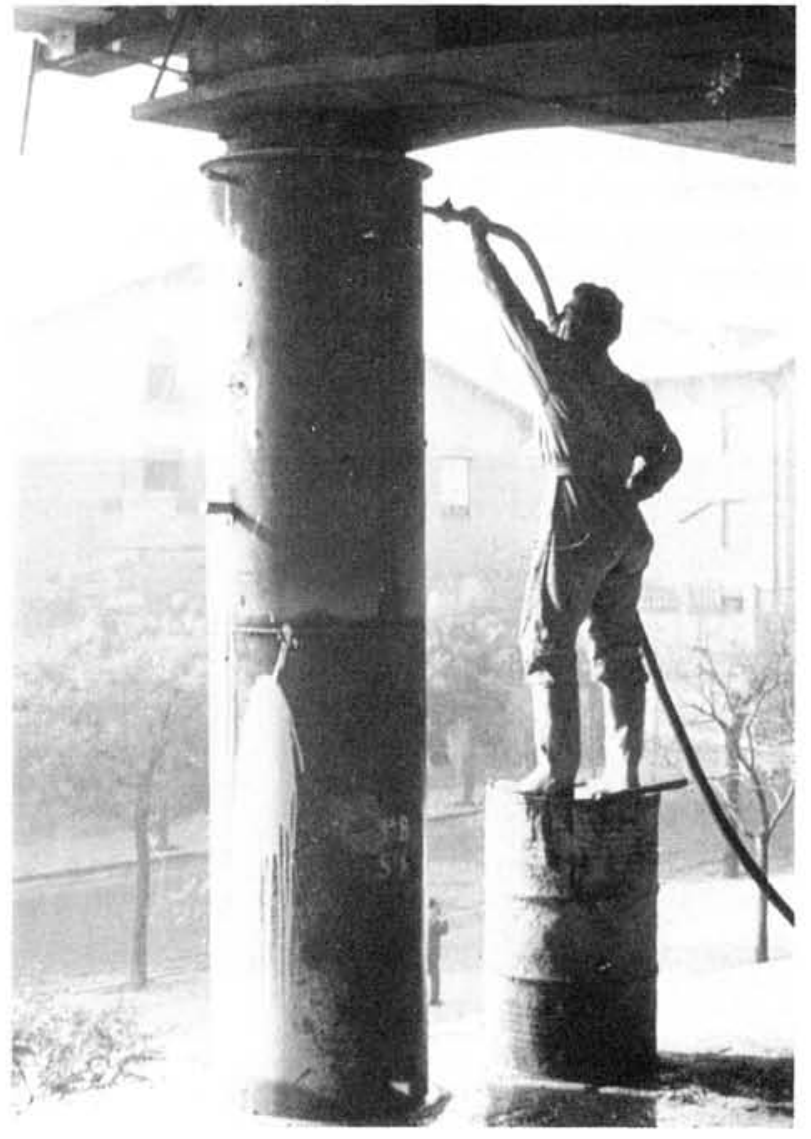

Fig. 22

En la Fig. 20 se puede apreciar la preparación y colocación de la armadura de una reparación de pilar por medio de un recrecido de unos $5 \mathrm{~cm}$, y en la $21 \mathrm{se}$ observa el pilar reparado. En las reparaciones con recrecido superficial se utiliza microhormigón para espesores hasta de 7,5 centímetros. La Fig. 22 muestra otro tipo de reparación de un pilar rectangular en que el recrecido se hace circular y la chapa exterior sive de encofrado y armadura complementaria.

\section{Colocación bajo agua}

Otra utilización muy extendida del microhormigón son las reparaciones bajo agua. Las caracteristicas que se obtienen en un microhormigón le hacen especialmente indicado para hormigones sumergidos. El microhormigón, en su utilización como hormigón sumergido, no presenta ningún problema en cuanto a deformaciones de retracción y termohigrométricas, incluso aunque se realice con un espesor de varios metros.

En la Fig. 23 se representa, en esquema, una reparación de cavernas, las cuales se producen con cierta frecuencia y en cuya reparación se usa un encofrado textil perdido. El saco se hincha con microhormigón adaptándose a las paredes de cada caverna sin pérdidas del material de reparación que, en otro caso, se saldria por http://informesdelaconstruccion.revistas.csic.es 
Ias juntas y grietas. En la Fig. 24 se puede ver una reparación, ya terminada, de este tipo.

En la Fig. 25 se puede apreciar un saco de ensayo con $12 \mathrm{t}$ de peso (6 $\mathrm{m}^{3}$ de volumen) que se utilizó en una reparación de la toma de refrigeración de una central nuclear, en la que el mar produjo una rotura y desprendimiento de unos $1.000 \mathrm{~m}^{3}$.

La Fig. 26 muestra el esquema de una reparación de un pilote que en la zona de carrera de marea suelen deteriorarse frecuentemente con material de soporte de madera, metálico y hormigón. En la Fig. 27 se observa la colocación, durante la bajamar, de la armadura y el encofrado textil que, por rapidez en estos casos, suele dotarse de una cremallera para su cierre longitudinal.

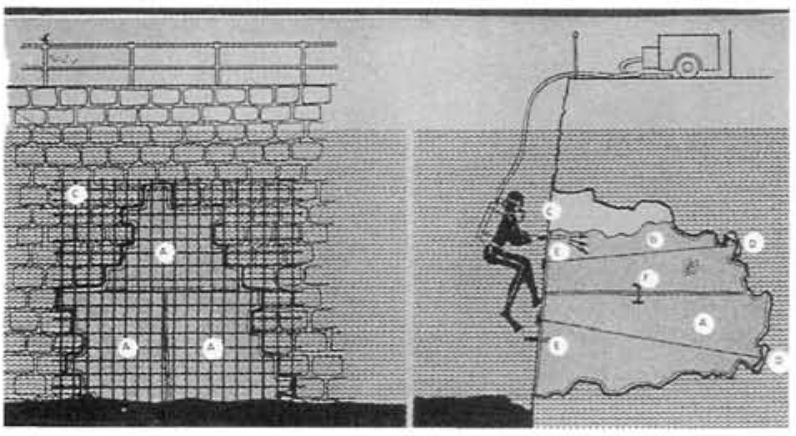

Fig. 23

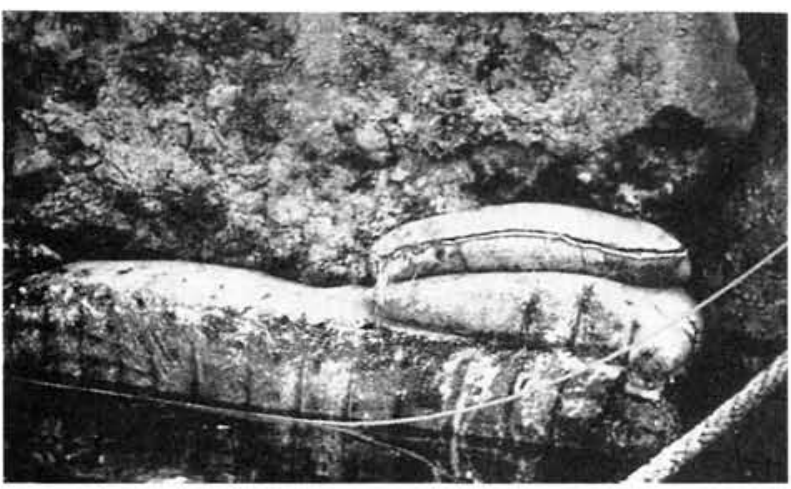

Fig. 24

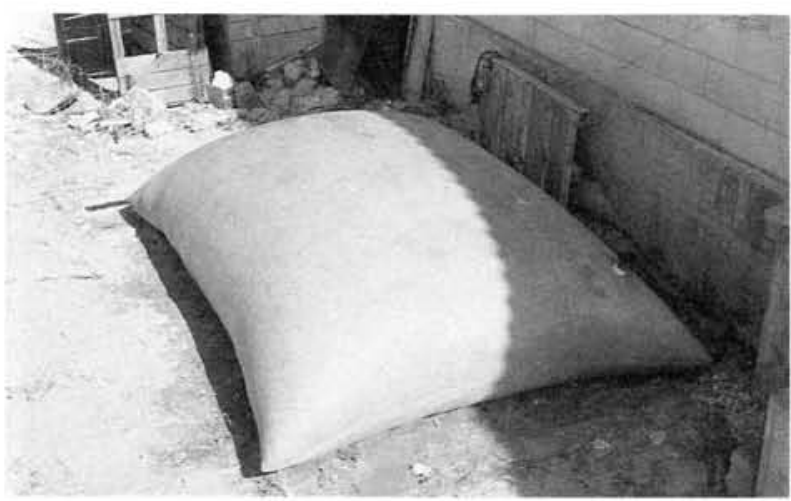

Fig. 25

(C) Consejo Superior de Investigaciones Científicas Licencia Creative Commons 3.0 España (by-nc)

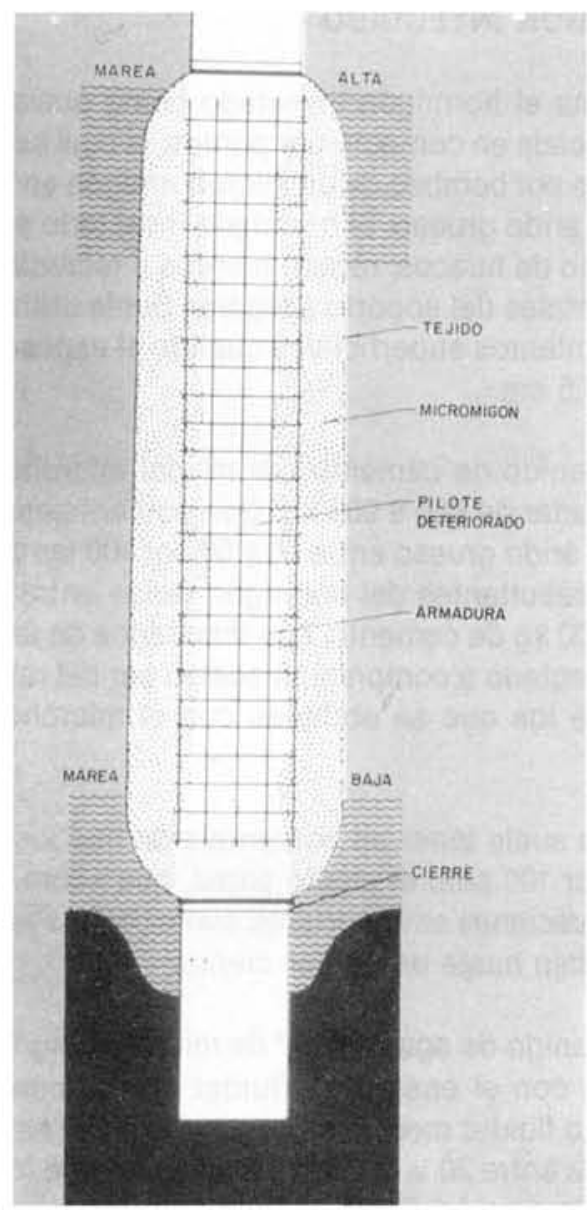

Fig. 26

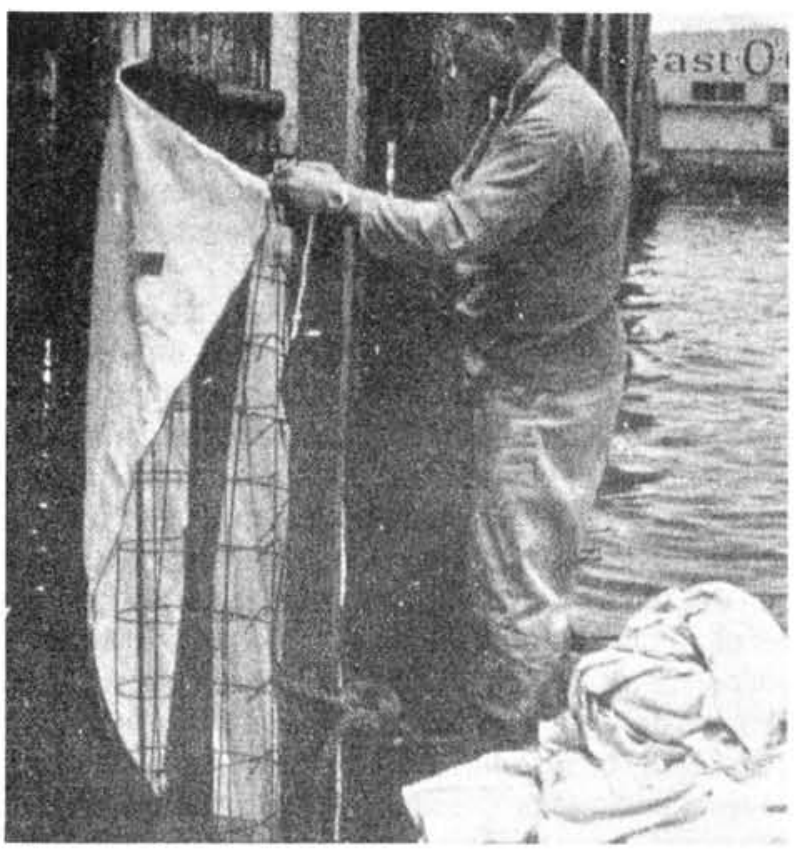

Fig. 27

http://informesdelaconstruccion.revistas.csic.es 


\section{HORMIGÓN INYECTADO}

Se define el hormigón inyectado como grava gruesa precolocada en contacto por puntos, la cual se ha consolidado por bombeo de un microhormigón en los huecos del árido grueso. El hormigón inyectado se aplica al relleno de huecos, revestimientos o recrecimientos superficiales del soporte a reparar. Suele utilizarse en recrecimientos superficiales cuando el espesor supera $\operatorname{los} 7,5 \mathrm{~cm}$.

El contenido de cemento por $\mathrm{m}^{3}$ del microhormigón suele variar de 600 a $900 \mathrm{~kg}$. Con porcentajes de huecos del árido grueso entre 40 y 50 por 100 las dosificaciones resultantes del hormigón varian entre 240-300 y $360-400 \mathrm{~kg}$ de cemento. Los resultados de un hormigón inyectado a compresión suelen ser del mismo orden que los que se obtienen con el microhormigón sólo.

El árido suele tener un porcentaje de huecos inferior al 40 por 100 pero el efecto pared, que sobre todo en las reparaciones es importante, suele llegar a veces ese porcentaje hasta un 60 por ciento.

El contenido de agua por $\mathrm{m}^{3}$ de microhormigón se determina con el ensayo de fluidez con el cono (flowcone). La fluidez medida en segundos suele estar comprendida entre $20 \pm 2$ para la mayor parte de los trabajos de reparación. Salvo en la fluidez, las características del microhormigón son las que hemos indicado anteriormente en el microhormigón como mortero de reparaciones.

Los ensayos para controlar el microhormigón del hormigón inyectado son los mismos que se han indicado para el microhormigón como mortero de reparación. La mayor parte de esos ensayos han sido preparados para microhormigones del hormigón inyectado.

El árido grueso precolocado puede ser natural o de machaqueo. El tamaño mínimo suele fijarse, en reparaciones, en $35 \mathrm{~mm}$. El tamaño máximo suele ser menos restrictivo que el que fija la EH-88 para hormigones convencionales. El cuarto que se menciona en el apartado del 7,2 de la EH- 88 suele fijarse en un tercio. Se ha comprobado que hasta tamaños máximos de 1:1, pueden utilizarse si se consiguen probetas que tengan tres veces la dimensión máxima del árido y una resistencia de 1,5 veces la requerida. Es frecuente realizar espesores de $10 \mathrm{~cm}$ con árido de $45-35 \mathrm{~mm}$. Se recomienda en estos casos utilizar árido grueso de machaqueo. La resistencia a compresión, cuando se utiliza árido de machaqueo, suele sobrepasar en un 20 por 100 la que se obtiene con árido rodado

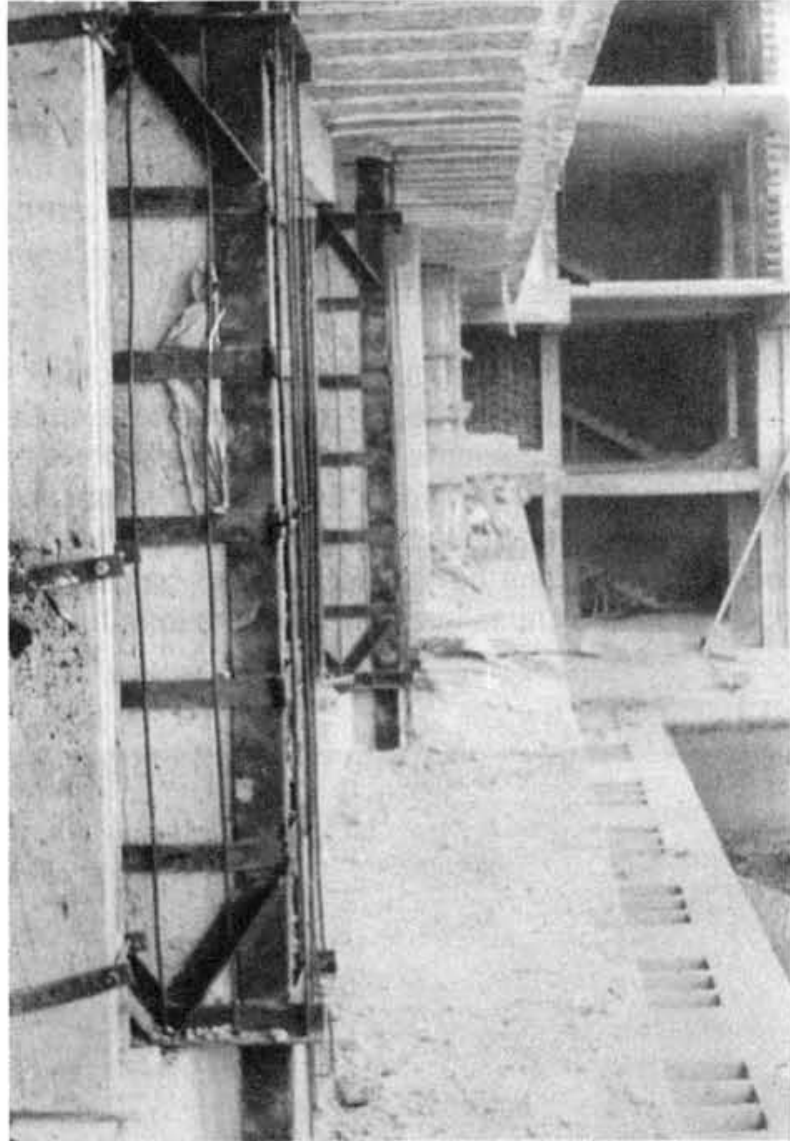

Fig. 28

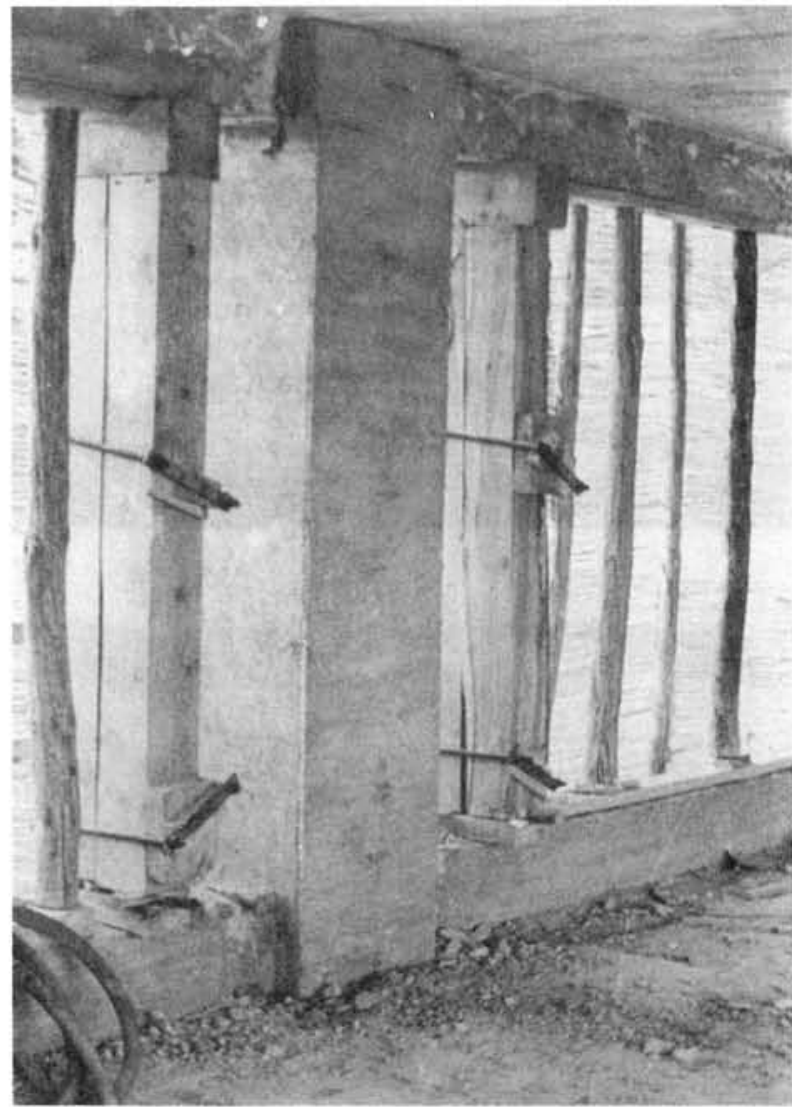

Fig. 29

http://informesdelaconstruccion.revistas.csic.es 


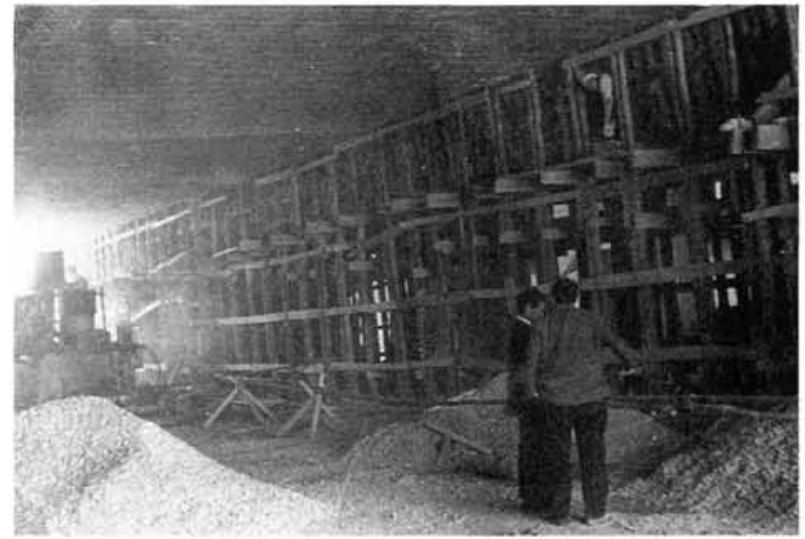

Fig. 30

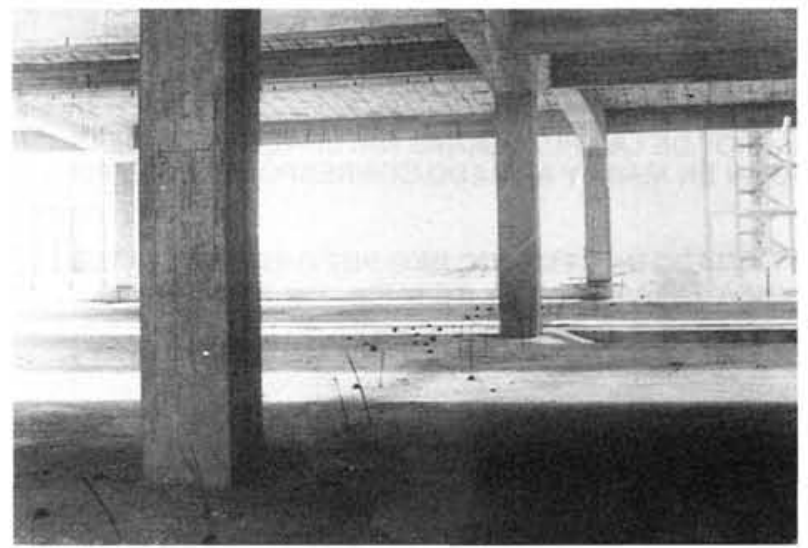

Fig. 31

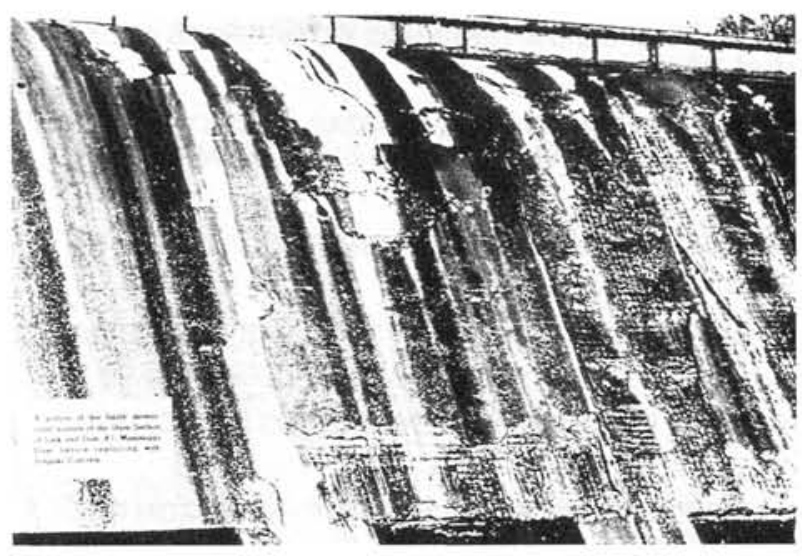

Fig. 32

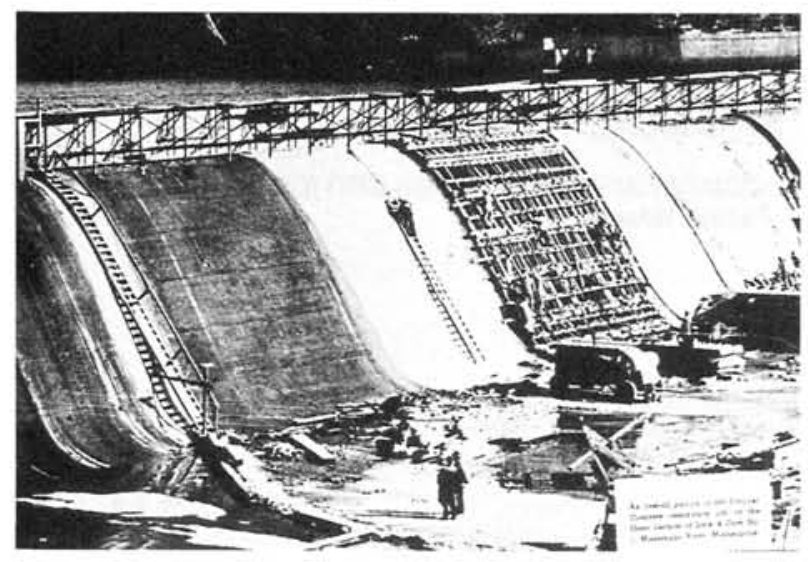

Fig. 33

(C) Consejo Superior de Investigaciones Científicas Licencia Creative Commons 3.0 España (by-nc)
La norma CRD-C-84-59 y la ASTM-C-943-80 indica el sistema para realizar las probetas de hormigón inyectado limitando, en la realización de probetas, el tamaño máximo al usar probetas cilíndricas de $300 \times 150$. En la práctica suelen realizarse probetas prismáticas 0 cúbicas de $200 \times 200$ y $300 \times 300$ mm, con una "tapa" similar a las indicadas por las normas mencionadas. Esas dimensiones permiten utilizar el árido hasta de $100 \mathrm{~mm}$ de tamaño máximo en la cúbica de $300 \mathrm{~mm}$, que es la que se utiliza con frecuencia en estos hormigones. A veces suele plantearse el problema de que los laboratorios no tienen prensas de la capacidad requerida cuando la resistencia es elevada.

Se han realizado ensayos para determinar la adherencia entre un hormigón convencional y otro inyectado. El método de ensayo ha consistido en la extracción de testigos, de $15 \mathrm{~cm}$ de diámetro y 76 de largo, que se han sometido a rotura, a flexión, mediante carga puntual en el centro o en la junta.

Cuando el soporte se ha tratado con chorro de arena los resultados han sido el 70 y 90 por 100 de la resistencia de un testigo sin junta de hormigón convencional. La tensión de rotura está entre 35 y $17 \mathrm{~kg} / \mathrm{cm}^{2}$. Cuando el tratamiento del soporte se hizo con una simple pasada, con cepillo de alambre, los resultados fueron del orden del 30 al 40 por 100 de los indicados.

La deformación del hormigón inyectado es del orden del 50 al 60 por 100 del hormigón convencional y de dosificación equivalente. Probablemente esta reducción se deba, en gran parte, al hecho de estar al árido grueso en contacto por puntos.

En la Fig. 28 se observa la reparación de un pilar con una armadura formada por cuatro angulares y las presillas correspondientes. La Fig. 29 muestra el pilar acabado con un recrecido de $10 \mathrm{~cm}$. Suele usarse esta armadura cuando la situación del pilar es crítica.

Finalmente se exponen diversos casos prácticos de reparación. Así, en la Fig. 30 se observa el encofrado para reparar una viga con hormigón en forma de $U$ alrededor de la viga construida con armadura pasiva. El hormigón de reparación fue postesado en dos sentidos tras el plazo de endurecimiento. En la Fig. 31 se muestra la estructura reparada. En la Fig. 32 se puede ver un Azud en Estados Unidos. Y en la 33 se observa parte de la reparación acabada. 